\title{
Commentary: Why do some patients with hypoplastic left heart syndrome have endocardial fibroelastosis?
} \author{
Carl L. Backer, MD, ${ }^{b}$ and Diane E. Spicer, $\mathrm{BSc}^{\mathrm{c}}$
}

Robert H. Anderson, BSc, MD, PhD (Hon), FRCPath, FRCS Ed (Hon), ${ }^{a}$ Elizabeth H. Stephens, MD, PhD, ${ }^{b}$

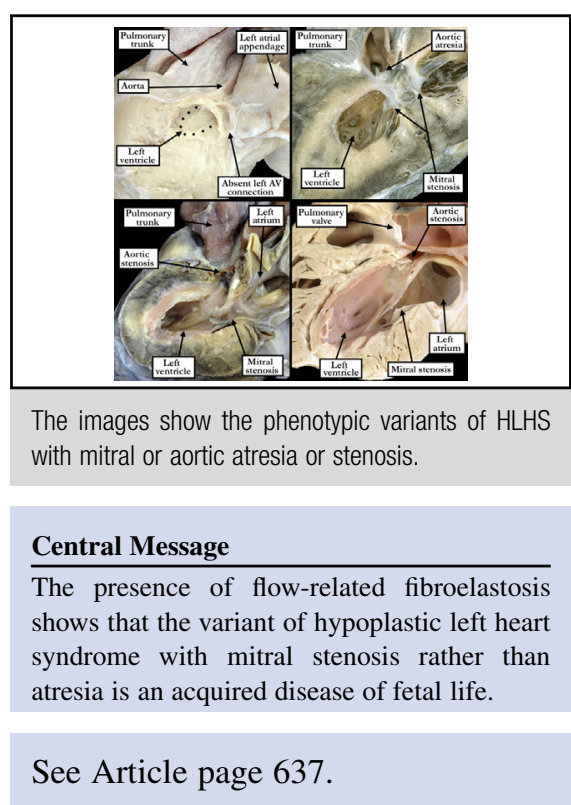

characterized by mitral stenosis rather than atresia. Weixler and colleagues ${ }^{4}$ provide strong evidence that the fibroelastosis is caused by abnormal flow through the cavity of the left ventricle. Such flow self-evidently can only occur when there is mitral stenosis, rather than mitral atresia. They have used sophisticated techniques to show that the fibroelastotic lining is produced from the endothelial lining of the left ventricle by the process known as endothelial-to-mesenchymal transformation. ${ }^{5}$ The notion that the fibroelastotic layer originated from the endocardium had, in fact, been promoted much earlier by Lurie. ${ }^{6}$ Making use of their elegant techniques, the Boston group now emphasize the relationship to the process initially observed as part of the production of the endocardial cushions that are essential for normal cardiac septation. Their findings are convincing, although they concede that surgical resection of the fibrotic layer is unlikely to provide a therapeutic panacea for those seeking to convert more patients to biventricular circulations.

By demonstrating the causal relationship between abnormal flow and development of the fibrotic layer, they nonetheless have now shown that the variant of hypoplastic left heart syndrome associated with mitral stenosis is an acquired disease of fetal life. ${ }^{7}$ This should be of obvious interest to those seeking to establish the genetic background 


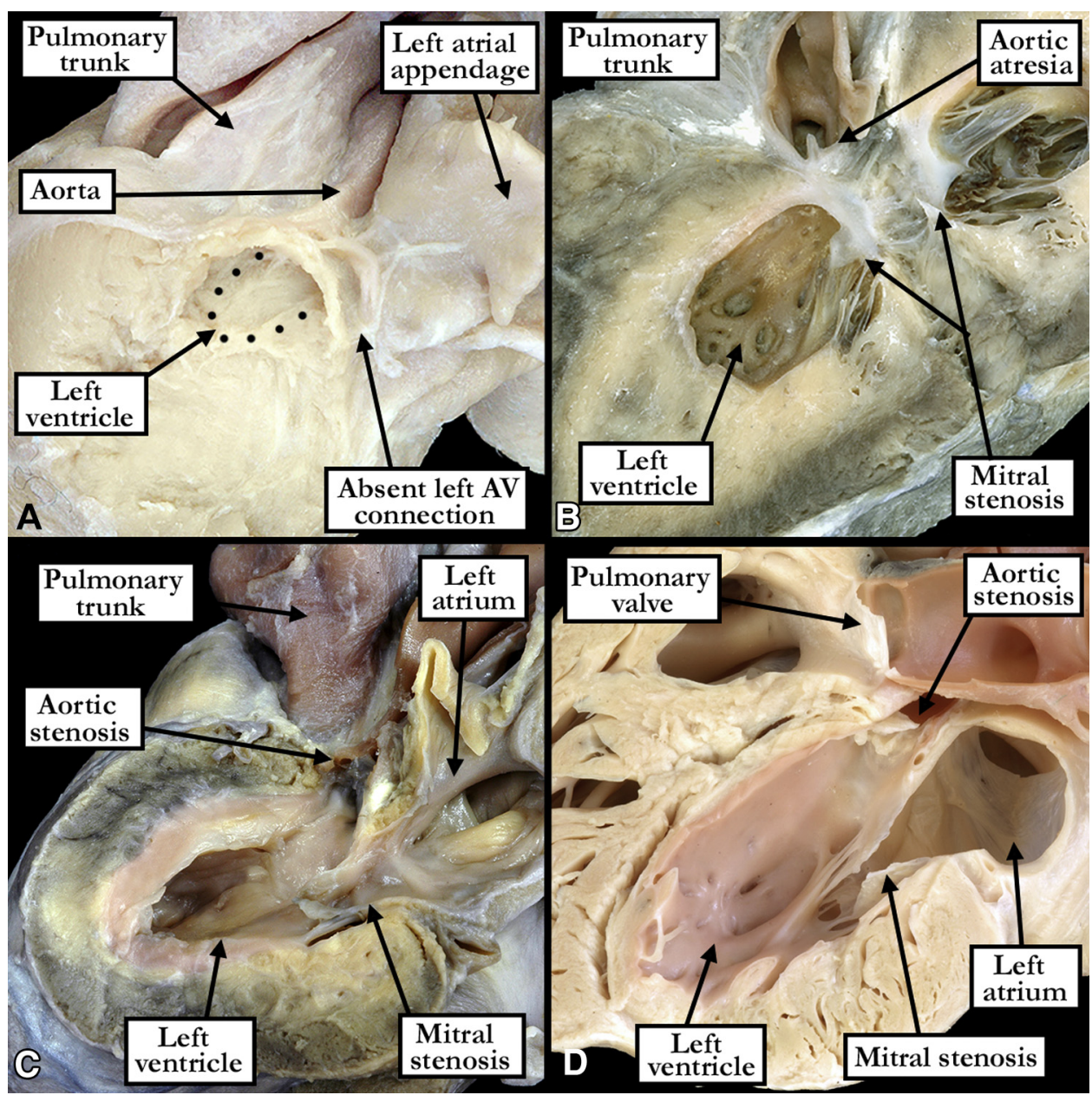

FIGURE 1. The images show the phenotypic variants of hypoplastic left heart syndromes with mitral or aortic atresia or stenosis. $A V$, Atrioventricular.

to the syndrome. This is because it is surely reasonable to presume that the disease itself did not begin to manifest until the completion of cardiac septation, calling into question the suggestion that the genetic background can be resolved by evaluation of animals models characterized by the presence of double-outlet right ventricle or atrioventricular septal defect. ${ }^{2}$ It remains the case that, unfortunately, we still do not have a good animal model for the patients who have the variant of hypoplastic left heart syndrome used in the current investigation of the Boston group. ${ }^{4}$ As Weixler and colleagues ${ }^{4}$ state, their own investigations continue, not least to assess whether they can establish a better means of combatting the problems produced by the presence of the fibroelastotic layer as they seek to treat more patients by using an algorithm leading to eventual biventricular repair. This is also of interest to those performing fetal interventions as to whether we can prevent or mitigate the development of fibroelastosis by improving flow during fetal life. Their findings of fibroelastotic lesions related to abnormal flow could also be relevant to those seeking to identify patients with the so-called hypoplastic left heart complex. ${ }^{3}$ Our own ongoing morphologic studies suggest that patchy areas of fibroelastosis are to be found in stored archival hearts from those who might have had this variant of the overall syndrome (Figure 1,D). We, along with surgeons and pediatric cardiologists, will be waiting with increasing interest for the future investigations as promised by the Boston group. Weixler and colleagues ${ }^{4}$ have pointed out that recurrence is a major problem. Prevention of recurrences should be a focus of future studies.

\section{References}

1. Crucean A, Alqahtani A, Barron DJ, Brawn WJ, Richardson RV, O'Sullivan J, et al. Re-evaluation of hypoplastic left heart syndrome from a developmental and morphological perspective. Orphanet $J$ Rare Dis. 2017;12:138

2. Liu X, Yagi H, Saeed S, Bais AS, Gabriel GC, Chen Z, et al. The complex genetics of hypoplastic left heart syndrome. Nat Genet. 2017;49:1152-9.

3. Tchervenkov CI, Jacobs JP, Weinberg PM, Aiello VD, Béland MJ, Colan SD, et al. The nomenclature, definition and classification of hypoplastic left heart syndrome. Cardiol Young. 2006;16:339-68. 
4. Weixler V, Marx GR, Hammer PE, Emani SM, del Nido PJ, Fries I. Flow disturbances and the development of endocardial fibroelastosis. J Thorac Cardiovasc Surg. 2020;159:637-46.

5. Eisenberg LM, Markwald RR. Molecular regulation of atrioventricular valvuloseptal morphogenesis. Circ Res. 1995;77:1-6.
6. Lurie PR. Changing concepts of endocardial fibroelastosis. Cardiol Young. 2010 20:115-23.

7. Grossfeld P, Nie S, Lin L, Wang L, Anderson RH. Hypoplastic left heart syndrome: a new paradigm for an old disease? J Cardiovasc Dev Dis. 2019;6:E10. 